\title{
School Food Environments and Policies in U.S. Public Schools
}

\author{
Daniel Finkelstein, PhD, EdM \\ Elaine Hill, BA \\ Mathematica Policy Research, Inc.
}

Rópert C. Whijtaker, DJD, IJJPH

Center for Obesity Rłesearch and Educanton

Terrpole Unjiversigy 


\section{Importance of the School Food Environment}

- Significant portion of children's daily food intake occurs in the school setting

- U.S. Department of Agriculture (USDA) sets standards for nutrient content of school meals

- Limited federal regulation on competitive foods and beverages in the school cafeteria 
Recent Efforts to Modify the School Food Environment

- Federal law required school districts to develop a "local wellness policy" by 2006

- Many states considering new legislation to improve nutritional standards in schools

- Despite increasing legislation, there is limited recent data on school food environments 
Variation in School Food Environments by Race/Ethnicity and SES

- U.S. public schools vary widely in the socioeconomic and racial/ethnic composition of student population

- Differences in school food environments could contribute to socjoeconomic and racjal/ethnic disparities in obesity 


\section{Study Objectives}

- Develop a summary score to characterize food environments and policies in U.S. public schools

- Examine variation in the summary score by school-level characteristics_ grade level, percentage racial/ethnic minority, and household income 


\section{Third School Nutrition Dietary Assessment Study (SNDA-III)}

- Nationally representative sample of public schools participating in USDA school meal programs in Spring 2005

- Sample sizes

-129 school food authorities (school districts)

-395 schools ( 3 schools per district)

$\checkmark$ Response rates

$-83 \%$ for districts and $95 \%$ for schools 


\section{SNDA-III Data Collection}

- Survey (districts, schools)

- Director of district nutrition programs

- School principal

- School food service manager

, Menu analysis of foods offered

- Data on free/reduced price Junch and race/ethnicity from Common Core Data (Natjonal Center for Education Statistics) 
Characterizing School Food Environments and Policies

- Examined "healthy" school food environments and policies in 3 domains

1) Policies and practices (8 items)

2) Competitive foods and beverages (4 items)

3) Content of USDA Iunches offered (5 items)

- Computed summary score reflecting total number (0-17) of healthy characteristics present in each school 


\section{Healthy Policies and Practices (8 items)}

1. Wellness policy addressing nutrition and PA

2. Nutrition or health advisory council

3. Nutrition education in every grade

4. No "pouring rights" contracts

5. No brand-name or chain restaurant items

6. Government fruit and vegetable program

7. Information on nutijient content of meals

8. Nutrient requirements for food purchasing 


\section{Availability of Competitive Foods and Beverages (4 items)}

1. No school store or snack bar

2. No fundraising involving sweet or salty snacks

3. No vending machines in school

4. Has vending, but not in food service area 


\section{Content of USDA Lunches Offered (5 items)}

1. Daily offering of fresh fruit and vegetables

2. No offering of whole or $2 \%$ milk

3. No offering of French fries

4. No offering of dessert

5. Average meal has $<=30 \%$ calories from fat 


\section{Data Analysis}

- Examined variation in summary score by school characteristics

- Grade level (elementary, middle, high)

- Racial/ethnic minority (percentage non-white)

- Household income (percentage free/reduced price Iunch)

- Created tertile categories for minority and income variables 


\section{Data Analysis (cont.)}

- Compared mean summary score across categories of school characteristics using analysis of variance

$\checkmark$ Incorporated features of complex sampling design

- Used school sample weights

- Standard errors adjusted to account for cjustering of schools within districts and sampling strata 


\section{SFEP Summary Score by Grade Level}

Means were significantly different across categories, $p<0.001$.

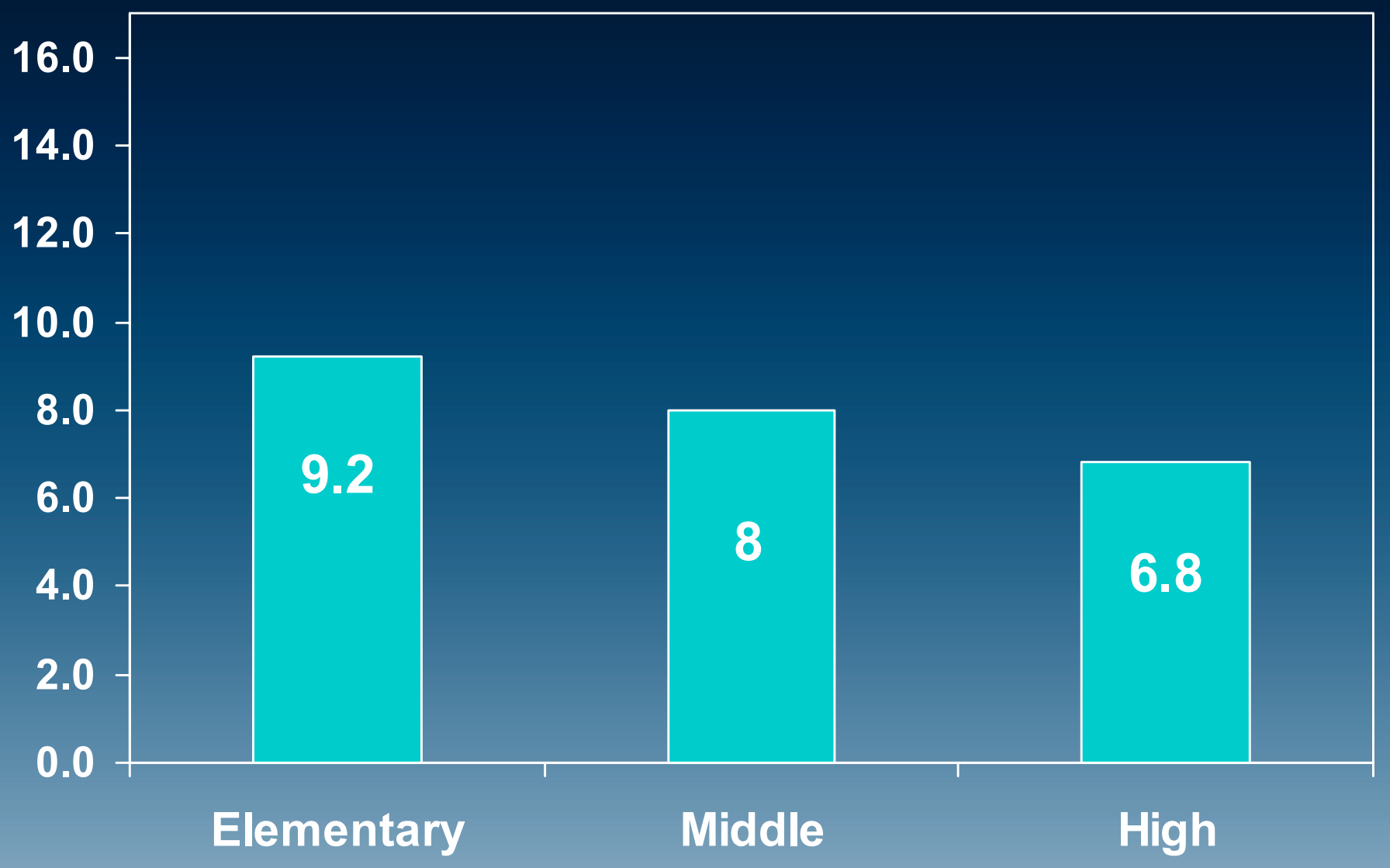




\section{SFEP Summary Score by Household Income}

Means were not significantly different across categories, $p=0.20$.

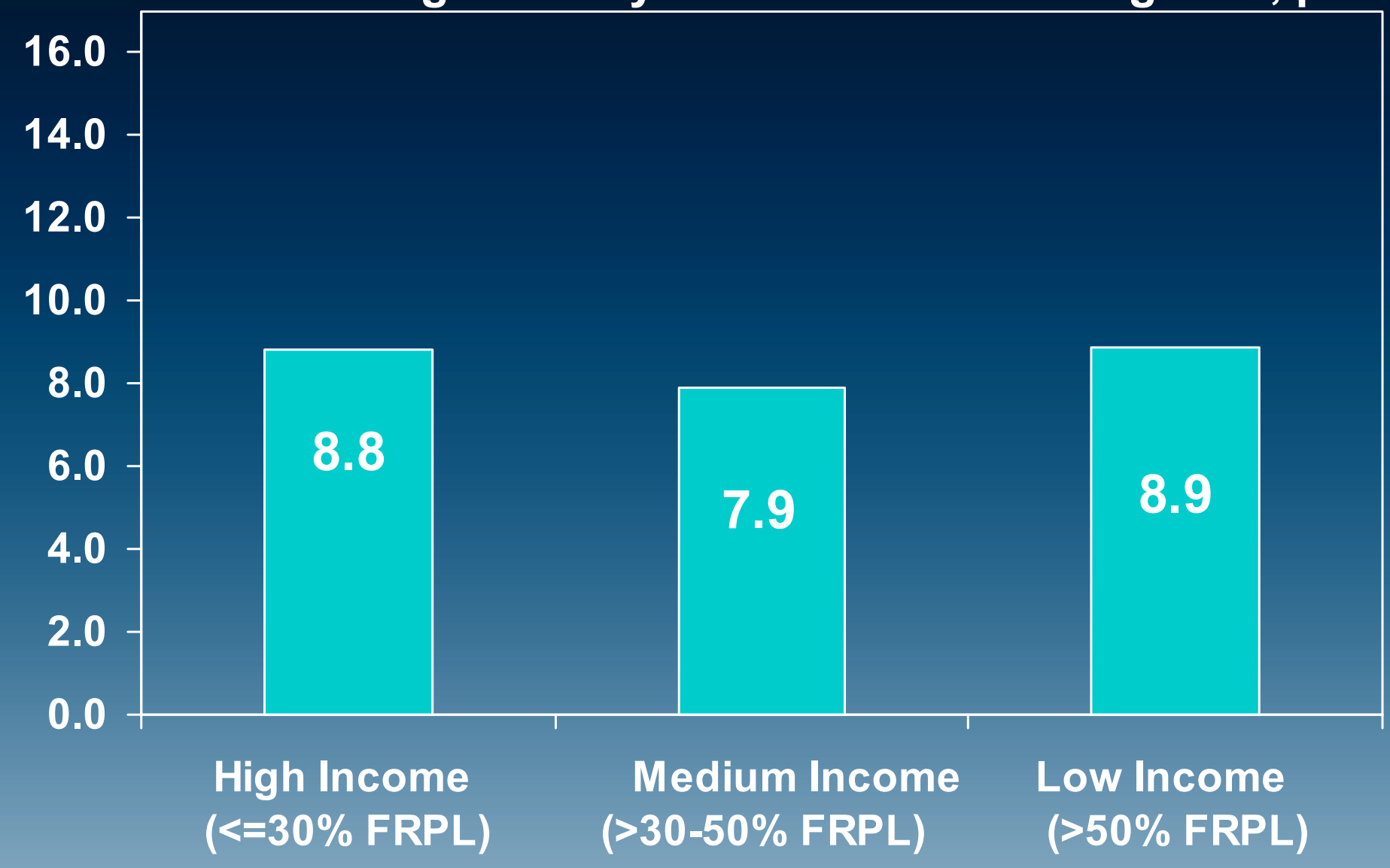




\section{SFEP Summary Score by Percentage Minority (Non-white)}

Means were marginally significantly different across categories, $p=0.06$.

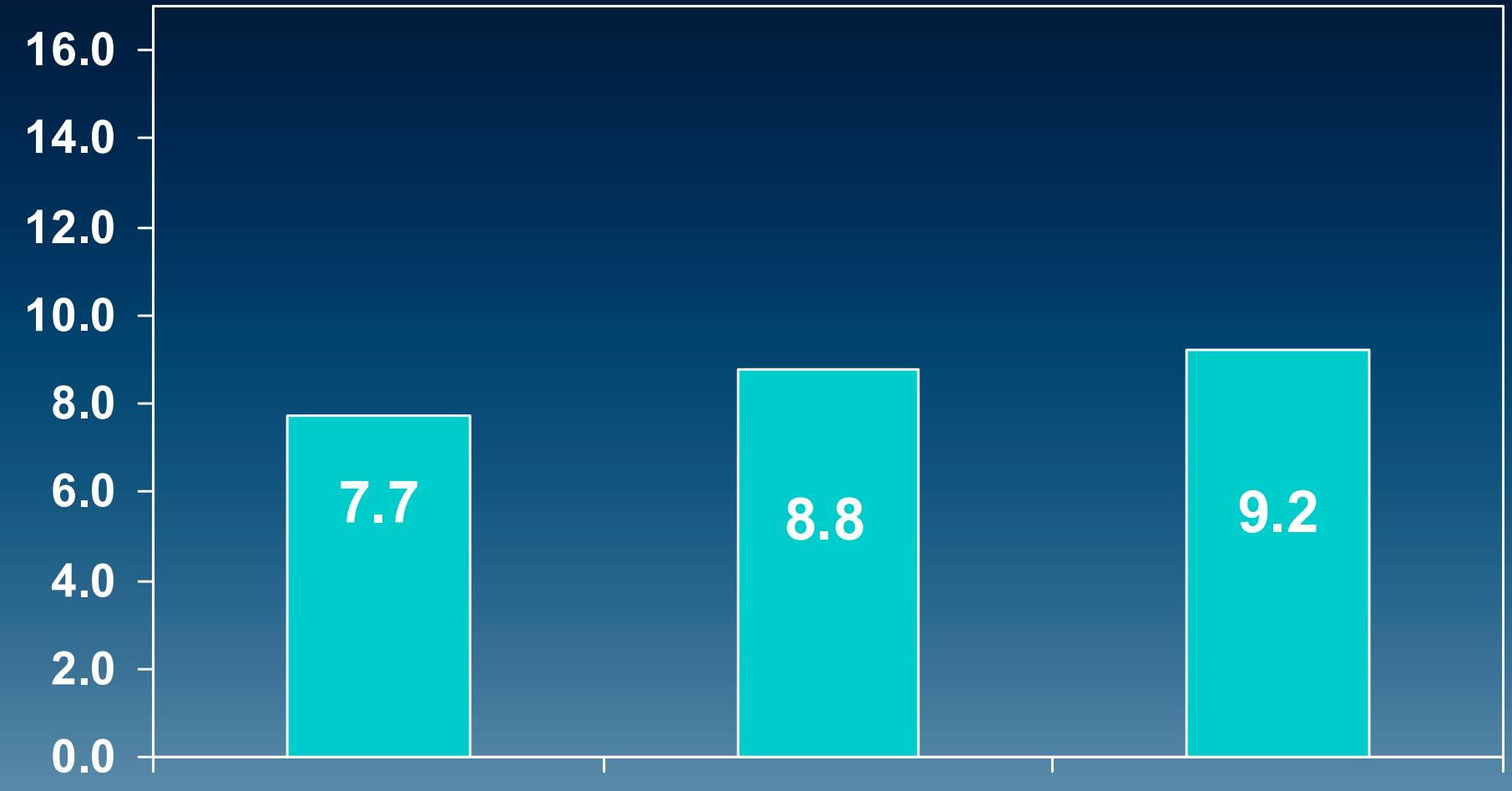

Low Non-white Medium Non-white High Non-white $(<=10 \%)$ $(>10-45 \%)$ $(>45 \%)$ 


\section{Conclusions}

- In a nationally representative sample of U.S. public schools, we found:

- Significant difference by grade level

- No difference by percentage of students certiffed for free or reduced-price lunch

- Marginally significant difference by the percentage who were racjal/ethnic minority 


\section{Implications}

- Schools have significant room for improving their food environments and policies

- Disadvantaged schools did not differ in their overall food environment 


\section{Sources of Funding}

- This analysis was funded by a grant from the Robert Wood Johnson Foundation (57930) in cooperation with U.S. Department of Agriculture (USDA), Food and Nutrition Service (FNS)

- Data collection and analyses for the third School Nutrition Dietary Assessment Study was funded under contracts with USDA, FNS (43-3198-4-0060 and AG-3198-D-05-007/1) 


\section{Acknowledgments}

Mathematica Policy Research, Inc.

- Ronette Briefel, DrPH, RD (Principal Investigator)

- Mary Kay Crepinsek, MS, RD

- Mary Kay Fox, MEd

- Philip Gleason, PhD

- Ander Wilson, BA

- Other members of the SNDA-III Project Team

USDA, Food and Nutrition Service

, Jay Hirschman, MPH, CNS

- John Endahl, PhD

- Patricja IJcKinney, IJS, RD

University of Mlinnesota

- MJary Story, PhD, RD 